OPEN ACCESS (C) (우웅

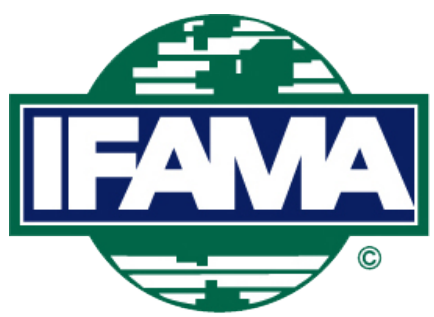

International Food and Agribusiness Management Review

Volume 23, Issue 2, 2020; DOI: 10.22434/IFAMR2019.0133

Received: 11 April 2019 / Accepted: 25 October 2019

\title{
Identifying risk in production agriculture: an application of best-worst scaling RESEARCH ARTICLE
}

Cosmos Atta ${ }^{\mathrm{a}}$ and Eric T. Micheels ${ }^{\circledR b}$

${ }^{a}$ Graduate student, ${ }^{b}$ Associate Professor, Department of Agricultural and Resource

Economics, 51 Campus Drive, University of Saskatchewan, Saskatoon, SK, Canada

\begin{abstract}
The identification and management of risk plays a significant role in reducing variability in farm income. The choice of risk management tools and strategies may depend on several factors, including the perceived importance of the risk and the perceived level of control that producers have in managing the risk. This study uses data from a 2017 survey of grain and oilseed farmers in Saskatchewan and employs a countbased approach of best-worst scaling and latent class cluster analysis to examine their perception of the most important sources of risk and the factors that influence these perceptions. The results suggest production and marketing risks, such as variation in output prices, rainfall variability, and changes in input prices, are the most important risks to farmers. However, results also reveal heterogeneity in responses to these identified risks, suggesting that a multifaceted approach is needed by farmers to address risk.
\end{abstract}

Keywords: risk, risk management, best-worst scaling, latent class cluster JEL code: Q10, Q12

\footnotetext{
${ }^{\circledR}$ Corresponding author: eric.micheels@usask.ca
} 


\section{Introduction}

Farm operators are confronted with input and output price volatility, unpredictable weather conditions, and changes in technology in their farming businesses. Variation in input and output markets contributes to production, marketing, financial, and institutional risk, among others (Guerin and Guerin, 1994). These risks, if not properly identified and managed, may lead to significant variability in farm income. While producers are aware of the underlying sources of these risks (Hwang et al., 2016; Lei et al., 2013; Oerke, 2006; Savary et al., 2012), farmers face sometimes significant costs in the attempt to reduce or mitigate events that lead to variations in farm revenue (Beckie et al., 1999). Farmers may therefore choose to manage risks that they have greater control over or that they feel are more important in determining farm profitability.

It has been noted that 'farmers' risk preferences may be more associated with their personal characteristics' (Hansson and Lagerkvist, 2012: 749). For example, farm or farmer characteristics such as age, farm size, risk perception, debt to asset ratio, off-farm income and education have been found to be significant determinants of farmers' risk preferences (Sherrick et al., 2004; Velandia et al., 2009). Differences in the perception of risk may also be influenced by the perceived ability of a farmer to fully or partially reduce or mitigate the risk. Studies by Shapira (1986) and MacCrimmon and Wehrung (1986) revealed that most managers believe that risk is manageable and controllable, and that the uncertainty of risk is not exogenously determined. Managers may therefore reject risk estimates and focus on getting new information needed in making adjustments to reduce the uncertainty (March and Shapira, 1987). This means that how managers view their level of control over production and marketing outcomes may influence their perception of, and need to control, the risks faced in their farm business.

The purpose of this paper is to examine how farm and managerial characteristics affect the importance of risk in the eyes of producers in Canada. Using data from a 2017 survey of Saskatchewan producers, we employ best-worst scaling (BWS) methods and latent class clustering to examine how farm and managerial characteristics are related to risk perceptions. In total, sixteen risk factors covering marketing, production, financial, institutional, and personal sources were used in designing the best worst questions. In addition, heterogeneity in producer responses is further examined using a latent class cluster analysis. Managerial differences are examined using Rotter's (1966) internal-external locus of control measure to examine how the farmer's perception of their ability to manage risks affects the importance of different sources of risk. In a similar vein to the work by Miller et al. (1982), we would expect that internal managers (those that feel that outcomes are largely shaped by their own actions as opposed to outside sources) would view sources of risk differently than external managers.

Recent work by Thompson et al. (2019) examined how farmers in the United States rate different risk management categories (production, marketing, financial, human, legal). They found that production risk was viewed as the most important, followed by financial and marketing risks. While the work by Thompson et al. (2019) provides much needed insight into the broad categories of risk that are important to producers, it is still unknown how producers rate the various sources of risk that occur within these categories. For example, variability in production may be a function of rainfall variability, other natural disasters such as hail or flooding, or the presence of pests and disease that could affect crop yield. In addition, personal factors, such as locus of control and risk attitude, may also influence the manager's perception of the importance of sources of risk based on their ability to manage the risk and their willingness to bear this risk. While perceived risks may differ from location to location and from farm to farm, a better understanding of the major sources of risk may help policy makers and extension personnel develop appropriate policy tools and dissemination strategies so producers can find the appropriate tool to match their own risk profile.

Using a count based BWS approach, our results show that respondents are more concerned with sources of risk that have direct impact on farm revenue. When respondents are categorized based on latent class clusters, two distinct groups emerge. The first is comprised of managers who place greater importance on financial and business risks, including product and input prices and the use of financial leverage. The other 
cluster is comprised of managers who place a greater importance on risk factors that influence yield and quality. Our results also show there was agreement among producers concerning the importance of risks such as rainfall variability and variation in input prices. Beyond production, marketing, and financial risks, respondents show some heterogeneity in the ranking of the importance of the other risks.

The remainder of the paper is structured as follows. First, we briefly review the literature on perception of risk in agriculture and provide some context for the location of our study. Next, we outline our experimental design and our methods for collecting data used in the analysis. We then examine the results of the BWS and the latent class cluster analysis. We conclude the paper with a discussion of the managerial implications of our findings.

\section{Farmers' perception of risk}

Risk in farming can stem from uncertainties related to weather, prices, government policies, global markets, as well as other sources. These uncertainties can lead to fluctuations in farm revenues and input costs, and as result, farm income. Extensive work has been done on sources of risk that affect the performance of commercial farm enterprises (Antón et al., 2011; Chavas and Shi, 2015; Harwood et al., 1999; Thompson et al., 2019). However, it is the perception of the particular risks faced by individual farmers that influence the development and adoption of strategies to manage risk in their production. The importance of these perceived risks may differ across specific types of production and among farmers.

According to Howden (2016), farmers in Saskatchewan face a set of production and economic risks, ranging from drought, excess moisture, frost, hail, pests and diseases, along with increasing costs of operation, low margins, and high fixed costs. All of these can lead to fluctuations in farm income and threaten the longterm viability of the farm business. This is not to say that producers in Saskatchewan are alone in dealing with varied sources of risk.

In addition to production and financial risks, producers in Saskatchewan are subject to increased levels of trade and policy risk in particular markets (i.e. chickpeas, lentils, canola). Given the high percentage of production exported, institutional risks such as changes in regional, national, and international trade regulations can influence production decisions as well as farm-gate prices. For example, restriction of imports through quotas and tariffs can negatively affect market access for export and alter production decisions of grain and oilseed farmers or reduce prices domestically. A recent example is the increase in tariffs on Canadian peas, lentils, and chickpeas by the Indian government (Cowan, 2018). These disruptions come at a time when seeded acres and production of lentils and canola have been increasing, while seeded acres for other crops have been relatively stable. Statistics on acreage, production, and exports (Table 1) show an increase in exports for canola seed, non-durum wheat, canola oil, and two important pulse crops from 2013-2016 (Government of Saskatchewan, 2016).

Factors affecting farm income, such as yield and price variability, are major sources of risk to farmers. Surveys of wheat and corn farmers in the United States and Australia revealed that farmers consider yield and price variability as major sources of risk to their farm business (Harwood et al., 1999; Kimura et al., 2010; Knutson et al., 1998). In other jurisdictions with different policy environments, these risks can vary in importance. For example, crop farmers in Switzerland reported that the role of costs in income variability was negligible, however price and yield risks were important sources of risk to farmers (El Benni and Finger, 2012). This could mean that respondents consider business risks and their effects on the farm's financial health to be more important to their farm business. Gabriel and Baker (1980) established that the financial risk of a firm is influenced by the degree of business risks inherent on the farm. That is, increased business risk adds to the variability in the net cash flow of the firm. The authors suggest that there is a trade-off between business risk and financial risk and that a decline in business risk would lead to the acceptance of greater financial risk (Gabriel and Baker, 1980). Moreover, the traditional business risks were found to be 
Table 1. Estimated acres, production, and volume of exports of major grain and oilseed crops in Saskatchewan (Statistics Canada, 2017).

\begin{tabular}{|c|c|c|c|c|c|}
\hline & \multirow[t]{2}{*}{ Crop } & \multicolumn{4}{|l|}{ Year } \\
\hline & & 2013 & 2014 & 2015 & 2016 \\
\hline \multirow{6}{*}{$\begin{array}{l}\text { Seeded area } \\
\text { (acres) }\end{array}$} & barley & $2,530,000$ & $2,020,000$ & $2,340,000$ & $2,475,000$ \\
\hline & spring wheat (non-durum) & $9,305,000$ & $8,475,000$ & $7,695,000$ & $6,870,000$ \\
\hline & durum & $4,365,000$ & $4,200,000$ & $4,900,000$ & $5,000,000$ \\
\hline & canola & $10,650,000$ & $10,750,000$ & $11,150,000$ & $11,250,000$ \\
\hline & lentils & $2,620,000$ & $3,010,000$ & $3,750,000$ & $5,105,000$ \\
\hline & chickpeas & 180,000 & 170,000 & 115,000 & 143,000 \\
\hline \multirow{6}{*}{$\begin{array}{l}\text { Production } \\
\text { (metric tons) }\end{array}$} & barley & $3,411,700$ & $2,172,900$ & $2,863,100$ & $3,374,700$ \\
\hline & spring wheat (non-durum) & $12,241,500$ & $9,150,500$ & $8,216,500$ & $7,989,600$ \\
\hline & durum & $5,633,600$ & $4,485,100$ & $4,572,200$ & $6,177,900$ \\
\hline & canola & $9,178,400$ & $7,971,900$ & $9,536,800$ & $10,682,100$ \\
\hline & lentils & $2,151,400$ & $1,902,600$ & $2,364,100$ & $2,742,000$ \\
\hline & chickpeas & 169,400 & 123,000 & 83,500 & 75,200 \\
\hline \multirow{8}{*}{$\begin{array}{l}\text { Total exports } \\
\text { (tons) }\end{array}$} & barley & & 751,942 & 564,873 & 565,383 \\
\hline & wheat (non-durum) & & $7,126,619$ & $7,914,679$ & $5,953,768$ \\
\hline & durum & & $4,867,095$ & $3,879,879$ & $3,449,715$ \\
\hline & canola seed & & $4,777,338$ & $4,739,243$ & $5,491,089$ \\
\hline & canola meal & & $1,885,372$ & $2,011,831$ & $2,676,723$ \\
\hline & canola oil & & $1,240,754$ & $1,305,272$ & $1,576,862$ \\
\hline & lentils & & $2,075,900$ & $2,606,566$ & $2,006,866$ \\
\hline & chickpeas & & 41,588 & 83,259 & 103,462 \\
\hline
\end{tabular}

more concerning to farmers when managing their farm businesses than other risks such as legal and human risks (Thompson et al., 2019).

Climatic and weather changes, cost of inputs, institutional factors, as well as pests and diseases, have also been reported in the literature as risk concerns to farmers. A study by Boggess et al. (1985) on causes of and farm managers' response to farm risk shows that crop farmers in Alabama and Florida rank rainfall variability, pests (insects, weeds and diseases), and the cost of operating inputs as their major sources of risk. Mixed farming and small grain producers in some selected states in the United States consider pests and diseases as major risks to their production, however this was of less concern to cotton farmers who view variability in input costs as their major source of risk (Patrick et al., 1985).

In Argentina, another country that exports a large share of production, changes in the economic and political situation are among the major risk concerns of Argentina's rice farmers (Pellegrino, 1999). Conventional and organic cash crop farmers in Norway reported crop prices, yield variability, and institutional risks as major sources of risk (Koesling et al., 2004). In Australia, climatic variability was ranked among the most significant risk concern to farmers in both Upper Eyre Peninsula of South Australia and Southwest Queensland, however, government policy was also important risk source to those in the Southwest Queensland (Nguyen et al., 2005). Organic grain farmers in the United States also consider risks resulting from weather, weeds, insects and deer and institutional factors such as non-severity of the USDA standards and non-enforcement of the organic standards across industry participants as their major risk concerns (Peterson and Kastens, 2006). Farmers did not consider marketing risks such as low prices and contracts not being honored as major risk factors (Peterson and Kastens, 2006).

These studies reveal that, although some level of similarity exists concerning the risks farmers face, there is also heterogeneity in farmers' perceived sources of risk depending on the type of farm, product produced, 
and the location of the farm business. As noted by Antón et al. (2011), risk attitudes of farmers vary with exposure and experience. The authors distinguished three different layers of risks and suggested that farmers should take the responsibility of managing some normal or frequent risk. Moreover, most studies have used traditional scaling approaches (i.e. Likert scales) in understanding farmers' perception of risk, while the current study adopts BWS methods which is a different approach in studying the relative importance of attributes.

\section{Experimental design}

To answer the question on the perception of relative importance of the various sources of risk to a farm operation, a survey of Saskatchewan grain and oilseed farmers was undertaken. The survey asked respondents to answer questions about their farm business, their attitude towards risk, as well as their perception on the level of control they have over factors that affect farm performance. Locus of control measures whether farmers consider their control of risk as dependent on their own abilities and efforts (internal locus of control) or determined by external forces (external locus of control), over which they have little or no control (Ochieng and Hobbs, 2016). Similar to the approach used by Thompson et al. (2019), we use as a BWS experimental design used to examine the perception of producers on the relative importance of the various sources of risks by asking them to select the 'best' and the 'worst' from a series of scenarios presented. However, we use a count-based approach as our design employs the count-based approach for Case 1 design (similar to the approach used in Ochieng and Hobbs (2016) and described in Louviere et al. (2013)). This section describes how the BWS was designed and implemented in this study.

The best-worst method was developed by Louviere and Woodworth (1991), and first published in 1992 (Finn and Louviere, 1992). The best-worst approach assumes some underlying subjective dimension, such as degree of importance, or degree of interest, and the researcher measures the location of some set of objects along this dimension (Auger et al., 2007). The current study assumes the underlying dimension to be the degree of importance and the objects to be the various sources of risk considered important by farmers. As a stated preference approach, it enables respondents to select the 'best' and the 'worst' attributes (sources of risk in reference to this study) in a repeated number of choice sets. Respondents are given the opportunity to select the two items in a choice set that maximize the difference between them on an underlying scale of significance (Erdem and Rigby, 2013). The best and worst choices in each scenario are counted, transformed into best-worst score and the information from the score is used to determine the relative importance of each attribute in the choice sets based on the number of times it is selected as 'best' or 'worst'.

The BWS approach helps in ranking many items on their importance to an individual (Erdem et al., 2012) and helps reduce probable inconsistencies in responses associated with ratings or rankings. This is especially important when respondents are presented long lists of items to be rated or ranked (Erdem and Rigby, 2013). The adoption of BWS methods for the study was motivated by assessing the various limitations of the other methodologies and the relative advantages of the BWS approach that overcomes the limitations of other methods of measurement approaches such as category rating scales or paired comparisons. According to Auger et al. (2007), BWS could help deal with the problems associated with the use of rating in terms of revealing the true preferences of respondents, since the approach forces respondents to make a discriminating choice among the issues under consideration. Lagerkvist (2013) also compared BWS and direct ranking in investigating consumer preferences for food labelling attribute and concluded that BWS improves individual choice predictions compared with direct ranking and generates more consistent dominance ordering of attributes importance. Recently, Thompson et al. (2019) used BWS and latent class modelling to examine how farmers in the United States view traditional sources of risk (production, marketing, finance). Their findings showed that for their sample of producers, the traditional sources of risk were more important than human or legal sources of risk.

In the design of a survey that will use BWS, it is important to ensure that the choice sets include all items identified and possible comparisons appear in an equal number of times (Louviere and Woodworth, 1991). Vermunt and Magidson (2014) also suggested that the combinations of items should be designed very carefully 
towards the goal that each item is shown an equal number of times and each pair of items is shown an equal number of times. The $2^{\mathrm{K}}$ factorial design, which ensured that each attribute is orthogonal and appears an equal number of times was employed (Coltman et al., 2011).

The design was applied to sixteen sources of risk identified based on a review of the literature. This yielded sixteen choice sets for the 'sources of risk'. The best-worst portion of the survey was designed such that there were four items in each choice set, and across all choice sets each source of risk appeared four times and was paired once with each other. Respondents were presented with a series of sixteen repeated choice tasks and were required to select the sources of risks they perceive to be important in their farm enterprise. This design represents a Case 1 BWS approach, as we are interested in the relative ratings between the sources of risk (Dumbrell et al., 2016; Louviere et al., 2013). Table 2 provides an example of a Case 1 choice set.

\section{Data collection}

An online survey of Saskatchewan grain and oilseed farmers was used to collect data. Survey respondents were drawn from a producer database owned by Insightrix ${ }^{\circledR}$ Research, Inc. (Saskatoon, SK, Canada). Two screening questions were used to ensure the participants were grain or oilseed producers and that they play a major role in making decisions concerning farm operations. A total of 600 grain and oilseed farmers responded to the survey. Participants were assigned unique identification codes to prevent identification of respondents and ensure anonymity and duplication of responses. Following these response validity checks, the responses retained constituted the data set. As shown in Table 3, respondents averaged 53 years of age, which is slightly less than the average age of Saskatchewan farm operators reported by Statistics Canada (55) in the 2016 Census of Agriculture (Statistics Canada, 2016). Most of the participants were male (77.2\%) and about $39.8 \%$ had a high school, vocational or technical education, $23.7 \%$ had college education, $28.2 \%$ had university education and about $7.7 \%$ had graduate level education. Most of the sampled population $(55 \%)$ had worked as farmers for over 31 years. A majority of respondents could be classified as small to medium-sized operations based on gross sales of less than CAN\$ 500,000. Almost one-fifth of respondents had sales of CAN\$ 1 million or more (18.5\%).

\section{Data analysis}

To determine farmers' perception of their most important sources of risk, the number of times a source of risk was selected as least important was subtracted from the number of times it was chosen as most important for all sixteen sources of risk. Case 1 BWS generally uses the standard practice of calculating best minus worst scores for each attribute which allows for ranking of the individual attributes (Adamsen et al., 2013; Flynn, 2010; Louviere et al., 2013). While more advanced methods, such as Maximum Likelihood Estimation of multinomial logit models have been used for Case 1 models in the past (Thompson et al., 2019), we employ the count method that has been used by other authors to analyze Case 1 best-worst data (Adamsen et al., 2013; Goodman et al., 2005; Ochieng and Hobbs, 2016), To estimate the relative importance of the sources of risk at the aggregate level, the difference between all best and worst counts was divided by the number of respondents to give BWS at the aggregate level for each item. Following Ochieng and Hobbs (2016), the best-worst scores were transformed into standard scores using Equation 1.

Table 2. Example of Case 1 choice set.

\begin{tabular}{lll}
\hline $\begin{array}{l}\text { Most important } \\
\text { (tick one) }\end{array}$ & $\begin{array}{l}\text { Of these sources of risks which will you consider as the } \\
\text { most and least important to your farm operation }\end{array}$ & $\begin{array}{l}\text { Least important } \\
\text { (tick one) }\end{array}$ \\
\hline$\square$ & Change in product prices & $\square$ \\
$\square$ & Change in world economic or political environment & $\square$ \\
$\square$ & Change in Government or producer policies & $\square$ \\
$\square$ & Change in input prices & $\square$ \\
\hline
\end{tabular}


Table 3. Socio-economic characteristics of respondents (Statistics Canada 2020a,b,c).

\begin{tabular}{|c|c|c|c|c|c|c|}
\hline $\begin{array}{l}\text { Socio-economic characteristics } \\
\text { of respondents }\end{array}$ & $\mathbf{N}$ & Min. & Max. & Mean (\%) & Std. dev. ${ }^{1}$ & $\begin{array}{l}\text { Comparative } \\
\text { census statistics }\end{array}$ \\
\hline Age & 577 & 19 & 91 & 53.1 & 14.1 & 55 \\
\hline \multicolumn{7}{|l|}{ Gender } \\
\hline Male & 463 & & & 77.2 & & 75.1 \\
\hline Female & 137 & & & 22.8 & & 24.9 \\
\hline \multicolumn{7}{|l|}{ Education } \\
\hline No. education & 4 & & & 0.7 & & 18.6 \\
\hline High school/voc/tech & 239 & & & 39.8 & & 49.0 \\
\hline College & 142 & & & 23.7 & & 20.7 \\
\hline University & 169 & & & 28.2 & & 11.7 \\
\hline Graduate school & 46 & & & 7.7 & & \\
\hline \multicolumn{7}{|l|}{ Experience } \\
\hline$<10$ years & 82 & & & 13.7 & & \\
\hline $11-20$ years & 96 & & & 16.0 & & \\
\hline $21-30$ years & 92 & & & 15.3 & & \\
\hline $31-40$ years & 156 & & & 26.0 & & \\
\hline$>40$ years & 174 & & & 29.0 & & \\
\hline \multicolumn{7}{|l|}{ Gross sales } \\
\hline$<$ CAN\$ 250,000 & 243 & & & 47.4 & & \\
\hline CAN\$ 250,000-499,999 & 94 & & & 18.3 & & \\
\hline CAN\$ 500,000-749,999 & 44 & & & 8.6 & & \\
\hline CAN\$ 750,000-999,999 & 37 & & & 7.2 & & \\
\hline$\geq$ CAN\$ $1,000,000$ & 95 & & & 18.5 & & \\
\hline
\end{tabular}

${ }^{1}$ Std. dev. $=$ standard deviation.

$$
\text { Standard score }=\frac{\operatorname{count}(\text { Best })-\operatorname{count}(\text { Worst })}{4 n}
$$

where $n$ is the number of survey respondents and 4 is the frequency with which each source of risk appears in the design.

According to Goodman et al. (2005), standardization helps in comparing different groups of respondents. Because the aggregate standard scores do not provide information on the relative importance of attributes, ratio scores were generated. The ratio scores standardize the best-worst scores to allow for comparison of the relative importance of attributes (sources of risks). Following Loose and Lockshin (2013), the ratio scores were estimated using Equation 2.

$$
\text { Weighting Factor } \text { important weight }=\frac{100}{\sum_{1}^{n} \sqrt{ }\left(\frac{B}{W}\right)}
$$

Where, $B=$ best scores and $W=$ worst scores.

Case 1 best-worst measurement does not reveal individual differences that may be present in the data, therefore, the standard deviation of individual best-worst scores was calculated to understand whether farmers are homogenous with their choices (Mueller and Rungie, 2009). A standard deviation above one provides suggests heterogeneity in the responses of producers (Mueller and Rungie, 2009). 
Table 4. Total best-worst scoring and aggregate rankings of risks. ${ }^{1}$

\begin{tabular}{|c|c|c|c|c|c|c|c|c|c|c|c|}
\hline & 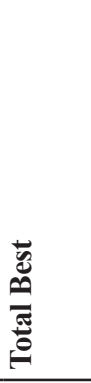 &  &  & 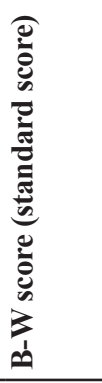 & 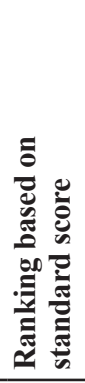 & 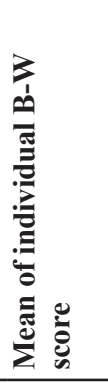 & 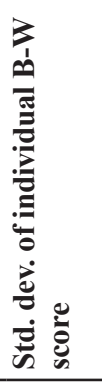 & 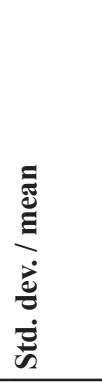 &  &  & 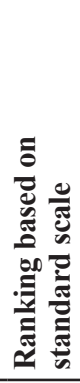 \\
\hline Change in product prices & 1,379 & 135 & 1,244 & 0.518 & 1 & 2.073 & 1.528 & 0.74 & 3.20 & 100 & 1 \\
\hline Rainfall variability & 1,151 & 210 & 941 & 0.392 & 2 & 1.568 & 1.962 & 1.25 & 2.34 & 73.1 & 2 \\
\hline Change in input prices & 1,047 & 265 & 782 & 0.326 & 3 & 1.303 & 1.475 & 1.13 & 1.99 & 62.2 & 3 \\
\hline Diseases and pests & 754 & 254 & 500 & 0.208 & 4 & 0.833 & 1.651 & 1.98 & 1.72 & 53.8 & 4 \\
\hline $\begin{array}{l}\text { Accidents and health / } \\
\text { disability }\end{array}$ & 731 & 467 & 264 & 0.110 & 5 & 0.440 & 2.112 & 4.80 & 1.25 & 39.1 & 5 \\
\hline Natural disasters & 746 & 522 & 224 & 0.093 & 6 & 0.373 & 2.037 & 5.46 & 1.20 & 37.4 & 6 \\
\hline $\begin{array}{l}\text { Unable to meet quality } \\
\text { requirements }\end{array}$ & 738 & 516 & 222 & 0.093 & 7 & 0.370 & 1.637 & 4.42 & 1.20 & 37.4 & 6 \\
\hline $\begin{array}{l}\text { Change in world economic } \\
\text { or political environment }\end{array}$ & 607 & 721 & -114 & -0.048 & 8 & -0.190 & 2.009 & -10.6 & 0.92 & 28.8 & 8 \\
\hline $\begin{array}{l}\text { Unable to meet contract } \\
\text { obligations }\end{array}$ & 381 & 512 & -131 & -0.055 & 9 & -0.218 & 1.621 & -7.44 & 0.86 & 26.9 & 9 \\
\hline Changes in interest rate & 371 & 572 & -201 & -0.084 & 10 & -0.335 & 1.727 & -5.16 & 0.81 & 25.3 & 12 \\
\hline Degree of debt to capital & 456 & 680 & -224 & -0.093 & 11 & -0.373 & 1.887 & -5.06 & 0.82 & 25.6 & 10 \\
\hline $\begin{array}{l}\text { Change in government or } \\
\text { producer policies }\end{array}$ & 482 & 723 & -241 & -0.100 & 12 & -0.402 & 1.894 & -4.71 & 0.82 & 25.6 & 10 \\
\hline Availability of loan funds & 377 & 744 & -367 & -0.153 & 13 & -0.612 & 1.851 & -3.02 & 0.71 & 22.2 & 13 \\
\hline Use of leverage & 170 & 910 & -740 & -0.308 & 14 & -1.233 & 1.492 & -1.21 & 0.43 & 13.4 & 14 \\
\hline Changes in technology & 138 & 976 & -838 & & 15 & -1.397 & 1.522 & -1.09 & 0.38 & 11.9 & 15 \\
\hline $\begin{array}{l}\text { Cost of securing } \\
\text { information }\end{array}$ & 72 & 1,393 & $-1,321$ & & 16 & -2.202 & 1.379 & -0.63 & 0.23 & 7.2 & 16 \\
\hline
\end{tabular}

${ }^{1}$ Std. dev. $=$ standard deviation; sqrt. $=$ square root.

\section{Best-worst scaling results: the relative importance of the sources of risk}

The ranking and importance of each of the sources of risk based on BWS standard score is presented in Table 4. Among all respondents, 'variations in product prices' and 'rainfall variability' are considered the first and second most important sources of risk followed by: (3) changes in input price; (4) pests and diseases; (5) accidents and health/disability; (6) natural disasters; and (7) unable to meet quality requirements.

The ranking based on the standard score only provides information on a basic ranking of the sources of risk but does not provide much information on the relative importance of these risks. To understand the relative importance, a probability ratio or interval scale was estimated from the best-worst scores following Equation 2. Column 11 of Table 4 shows the ranking based on the ratio score (measure of relative importance). We rescaled 'change in product prices' to be equal to 100 because it is the risk with the highest-ranking interval. The standardized square root interval scale, which reveals the relative importance of the attributes, did not reveal much change in relation to the ranking of the most important risk sources. The top five risks were the same as the ranking based on the standard score. 'Changes in product prices' was still ranked the most important risk followed by: (2) rainfall variability; (3) change in input prices; (4) pests and diseases; and (5) accidents and health/disability. The ranking based on the standardized square root interval scale means that, 
compared to 'changes in product prices' considered by producers as the most important, 'rainfall variability' and 'change in input prices' are 0.73 and 0.62 times as important as changes in product prices. The results also reveal a large interval between the most important risk (ranked $1^{\text {st }}$ ) and the other risk sources considered important to producers. This points to the importance of the most important risk 'changes in product prices' relative to the other risks. The second through fourth highest ranked risks were significantly important, though to a lesser degree.

In all, the results show that Saskatchewan grain and oilseed farmers view production and price risks (both input and marketing) to be more important relative to health and personal risks. Many of the more highly rated risks were associated with the aspects of the farm that farmers have less control over, such as rainfall and product prices. This would suggest that respondents are more concerned with risks that affect the financial health of the farm. For example, significant yield losses due to weather factors such as excessive or limiting rainfall, natural disasters and lower prices negatively affect the quantity of output that can be sold, or the revenue generated from sale of output. Increases in input prices can significantly increase production costs, reduce margins, and have a negative impact on net cash flow. Moreover, the importance of business risks to producers may be explained by the little control producers have over these risks and their actions do little to alleviate them. The result is consistent with other studies that also found business risk to be more important to famers relative to other risks (El Benni and Finger, 2012; Kimura et al., 2010; Thompson et al., 2019)

As indicated earlier, Case 1 best-worst measurements, which require respondents to choose the best and worst (on some subjective scale) from a set of objects, fail to reveal the individual differences that may exist in the responses because it provides results on the aggregate ranking of the risks. To further explore heterogeneity in the data, the standard deviation of the individual best-worst score over all respondents was calculated to measure the variations in the importance of the attribute across the sample. The results show the standard deviation of all sixteen sources of risk (Column 7 of Table 4) are above one revealing the presence of heterogeneity of responses among producers regarding the most important sources of risk to their farm business.

To determine the extent of heterogeneity of responses, the ratio of standard deviation to the mean was calculated for each risk (Column 8 of Table 4). While greater absolute ratios indicate greater heterogeneity in responses, ratios that are zero or close to zero suggest absolute agreement or greater uniformity in the extent to which a respondent considers a particular risk as important or not. There is greater agreement on the relative importance of risks for: (1) changes in product prices; (2) changes in input prices; (3) use of leverage; (4) rainfall variability; (5) changes in technology; and (6) cost of securing information. However, there is greater heterogeneity (as measured by the ratio of standard deviation compared to the mean) for: (1) changes in world economic or political environment; (2) natural disasters; (3) changes in government or producer policies; (4) degree of debt to capital; (5) changes in interest rate; and (6) accidents and health/ disability.

\section{Latent class cluster analysis}

Based on the observed heterogeneity in risk importance, a latent class cluster analysis was estimated to provide further insights into the nature of the heterogeneity in producers' responses to their perception of most important sources of risk. The latent class cluster method assumes that unique segments in data exist and there are respondents who have similar choices within segments but differ with their preferences across segments (Loose and Lockshin, 2013). It identifies segments within the population and uses co-variation among individual observed preference scores (observed best-worst scores in this case) as a measure of utility to predict individuals' unique membership in a specific segment on a probability basis (Loose and Lockshin, 2013; Umberger et al., 2010). According to Ganesalingam et al. (2009: 2) 'the method assumes $\mathrm{k}$ latent groups or latent classes underlying the data set and that each case belongs to only one group and the number of classes and their sizes are not known a priori.' Coltman et al. (2011) also explain that the approach allows for estimating a maximum likelihood-based model that accounts simultaneously for similarities and 
differences between attributes. The latent class cluster method was used in this study to classify producers based on how they rate the importance of each of the sources of risk to their farm operations, and how the structural characteristics of the farm and farmers influence these perceptions.

Following Vermunt and Magidson (2002), the following multinomial logit model was selected in estimating the latent class cluster model:

$$
f\left(\mathrm{y}_{\mathrm{i}} \mid z_{i}, \theta\right)=\sum_{k=1}^{k} \pi_{\mathrm{k} \mid \mathrm{z}_{\mathrm{i}}} \prod_{j=1}^{J} f_{k}\left(y_{i j} \mid z_{i}, \theta_{j k}\right)
$$

Where $y_{i}$ denotes an object's scores on a set of observed variables (in this case, the individual best worst scores for all the sources of risk and risk management strategies used as indicators or dependent variables in the cluster analysis), $z_{i}$ represents object i's covariates, $\mathrm{k}$ is the number of clusters, $\Pi_{k \mid z i}$ indicates the prior probability of belonging to latent class or cluster $\mathrm{k}$ given covariates $z_{i}$, J denotes the total number of indicators and $\theta$ is the model parameters.

The individual best-worst scores for the sixteen sources of risk are used as the dependent variable and served as indicators in the cluster analysis to understand how respondents are heterogeneous in their perception of the most significant sources of risk. To understand what influences their perception of risks, farm and farmer characteristics were included as explanatory variables that serve as covariates in the cluster analysis to help further predict the unique membership of respondents into the clusters identified. The covariates used in the model include off-farm income, farm size, household income, farmer's experience, internal and external locus of control, risk attitude (measured using a priori categorized questions in a Likert scale form), education, age and gender.

We estimated several latent class models in Latent Gold 5.1 and the Akaike Information Criterion (AIC) was used to determine the model with the best fit. According to Fraley and Raftery (1998), the most popular set of model selection tools in latent class cluster analysis are the Akaike, Bayesian, and consistent Akaike information criteria, or AIC, BIC, and CAIC (Fraley and Raftery, 1998). The AIC was used as the criteria in the selection of the best model because it can address the drawbacks in either under-fitting or over-fitting a model because it takes into account parsimony by adjusting the log likelihood goodness-of-fit values to account for the number of parameters in the model (Snipes and Taylor, 2014). The lower the value of the AIC, the better the model fit (Fabozzi et al., 2014). Other classification statistics such as classification errors was considered to ensure that the model has an acceptable and comparatively low ratio of classification error (Coltman et al., 2011). Based on the information criteria and the classification errors, two distinct classes were identified because it had the lowest AIC value and low ratio of classification errors.

The mean best-worst scores and characteristics of the latent class cluster presented in Table 5 reveal the relative importance of the sources of risks across segments. The mean best-worst scores are based on the

Table 5. Characteristics of latent class clusters.

\begin{tabular}{llllll}
\hline & \multicolumn{2}{l}{$\begin{array}{l}\text { Cluster 1 }- \text { Financial and business risk } \\
\text { managers 64\% }\end{array}$} & & \multicolumn{2}{l}{$\begin{array}{l}\text { Cluster 2 - Production and marketing risk } \\
\text { managers 36\% }\end{array}$} \\
\cline { 2 - 3 } \cline { 5 - 6 } & Most important sources of risk & Mean & & Most important sources of risk & Mean \\
\hline Most & change in product prices & 1.88 & & rainfall variability & 2.50 \\
$2^{\text {nd }}$ & change in input prices & 1.39 & & change in product prices & 2.33 \\
$3^{\text {rd }}$ & rainfall variability & 1.15 & & natural disasters & 1.62 \\
$4^{\text {th }}$ & degree of debt to capital & 0.35 & & diseases and pests & 1.47 \\
$5^{\text {th }}$ & changes in interest rate & 0.32 & & unable to meet quality requirements & 1.07 \\
$6^{\text {th }}$ & diseases and pests & 0.30 & & change in input prices & 1.01 \\
$7^{\text {th }}$ & & & & accidents and health/disability & 0.87 \\
\hline
\end{tabular}


cluster level conditional probabilities for each source of risk and provide an indication of importance of the risk to producers. Some covariates including off-farm income, debt-to-asset ratio, age, external locus of control and household income were also found to be significant in predicting the unique membership in a specific latent class (Table 6).

Cluster 1 was the larger of the two clusters as it was made up of $64 \%$ of survey respondents. Producers in cluster 1 consider risk from production, marketing and financial sources as important to their farm operation, therefore we term this cluster 'Financial and business risk managers'. Variation in product prices, input prices and rainfall are the three most important risks to farmers in this cluster. Financial risks such as the use of leverage (as measured by debt-to-equity) and changes in interest rates were also important to producers in the cluster. Greater price volatility means higher costs of managing risks (Tothova, 2011) and rainfall variability could potentially cause output fluctuation which threatens the stability of farm income. It may not be surprising farmers concerned about leverage and interest rates consider production risks as important to their business, as these would affect their ability to repay loans as they come due.

The remaining $36 \%$ of respondents were categorized in cluster 2 . Producers in cluster 2 focus more on risks from production and markets as important to their farm business, therefore we term these producers 'Production and marketing risk managers'. Important risks to these producers include rainfall variability, variation in product prices, natural disasters, pests and diseases, ability to meet quality requirements, variations in input prices, accidents and health/disability. Absent from the top rankings in cluster 2 are any risks directly relating to financial management. The ranking of inability to meet quality requirements among the top risks may be due to a greater reliance on production contracts for these farmers, as contract terms specify grade and protein characteristics. For example, failure to produce grain at the contracted standard may force the farm to fulfil the contract by procuring the contracted amount in the cash market. ${ }^{1}$ Producers in the 'Production and marketing risk management' cluster consider pests and diseases as relatively more important compared to those in the 'Financial and business risk' cluster. It follows that these producers also view the risk in meeting quality requirements as considered important, since pests and diseases could affect the grade received when production is delivered.

Finally, the results from the covariates show that producers who do not earn off-farm income are $61 \%$ more likely to belong to the 'Financial and business risk management' cluster (Table 7). This may reflect

\footnotetext{
${ }^{1}$ The Canadian Grain Commission has comprehensive grading factors such as artificial stain, blackpoint, darkened kernels, fertilizer pellets among others used to assess the quality of producers' grains which determines the price to be paid to producers. Inability to meet the grain quality may deny producers the opportunity to earn higher premium offered to quality grain and negatively affects farm revenue.
}

Table 6. Covariates predicting cluster membership.

\begin{tabular}{lcll}
\hline Covariates & Wald & $\boldsymbol{P}_{\text {-value }} \mathbf{1}^{\mathbf{2}}$ & Mean \\
\hline Off-farm income & 4.39 & 0.036 & $* *$ \\
Sales & 0.16 & 0.69 & $\mathrm{~ns}$ \\
Gender & 0.21 & 0.65 & $\mathrm{~ns}$ \\
Experience & 0.25 & 0.62 & $\mathrm{~ns}$ \\
Debt/asset ratio & 16.35 & 0.001 & $* * *$ \\
Age & 17.17 & 0.001 & $* * *$ \\
Type of farm & 0.65 & 0.72 & $\mathrm{~ns}$ \\
Internal locus & 0.92 & 0.34 & $\mathrm{~ns}$ \\
External locus & 3.86 & 0.05 & $*$ \\
Risk averse & 0.08 & 0.77 & $\mathrm{~ns}$ \\
Risk seeking & 2.63 & 0.10 & $\mathrm{~ns}$ \\
Education & 1.98 & 0.16 & $\mathrm{~ns}$ \\
Household income & 7.57 & 0.006 & $* * *$ \\
\hline
\end{tabular}

$1 * P<0.1 ; * * P<0.05 ; * * * P<0.01 ; \mathrm{ns}=$ not significant. 
Table 7. Probabilities of significant covariates by class cluster.

\begin{tabular}{|c|c|c|}
\hline Covariates & $\begin{array}{l}\text { Financial and business risk } \\
\text { management }\end{array}$ & $\begin{array}{l}\text { Production and marketing risk } \\
\text { management }\end{array}$ \\
\hline & \multicolumn{2}{|l|}{ Probability } \\
\hline \multicolumn{3}{|l|}{ Off-farm income } \\
\hline No & 0.61 & 0.39 \\
\hline \multicolumn{3}{|l|}{ Debt/asset ratio } \\
\hline $0 \%$ & 0.36 & 0.64 \\
\hline $0.01-24.99 \%$ & 0.67 & 0.33 \\
\hline $25.00-50.00 \%$ & 0.80 & 0.19 \\
\hline$>50 \%$ & 0.95 & 0.05 \\
\hline \multicolumn{3}{|l|}{ Age } \\
\hline$<45$ years & 0.92 & 0.08 \\
\hline $45-54$ years & 0.70 & 0.30 \\
\hline $55-64$ years & 0.56 & 0.44 \\
\hline$\geq 65$ years & 0.41 & 0.59 \\
\hline \multicolumn{3}{|l|}{ External locus } \\
\hline Disagree & 0.55 & 0.45 \\
\hline Agree & 0.60 & 0.40 \\
\hline Strongly agree & 0.79 & 0.21 \\
\hline \multicolumn{3}{|l|}{ Household income } \\
\hline$<$ CAN\$ 49,999 & 0.75 & 0.25 \\
\hline CAN\$ 50,000-99,999 & 0.64 & 0.36 \\
\hline CAN\$ $100,000-149,999$ & 0.62 & 0.38 \\
\hline$>$ CAN\$ 150,000 & 0.53 & 0.47 \\
\hline
\end{tabular}

the increased needs of these producers to internally manage cash flow (relative to farms with off-farm income). Conversely, those in the 'Production and marketing risk management' cluster may be able to use off-farm income to mitigate the effects of lower production or farm revenue. Producers with low debt-toasset ratios are likely to be in the 'Production and marketing risk management' cluster as they may place greater attention to sources of production risk as financial risk, as measured through financial leverage, is not perceived to be an issue. As debt levels increase, the probability of farmers belonging to the 'Financial and business risk management' cluster increases. Interestingly, producers in the 'Production and marketing risk management' cluster who are more likely to have zero debt to asset ratio are those who did not consider any of the financial risks important.

The results also reveal the probability of belonging to the 'Financial and business risk management' cluster decreases as farmers' age increases. This follows the typical pattern observed in the use of leverage as the farm business matures. In addition, those who believe risk in the farm is due to forces beyond their control and that control of risk is less dependent on their own ability and effort (external locus of control) are likely to be members of the 'Financial and business risk management' cluster. A closer examination of the 'Financial and business risk management' cluster shows that most of the risks are those to which farmers have less control over and may explain why a greater percentage of producers with external locus of control are found in this cluster. Producers in all household income categories are more likely to belong to the 'Financial and business risk management' cluster, however this probability decreases as household income increases. As household income increases, the capacity of producers to finance their farm operation internally improves and these firms may be less reliant on external financing such as borrowing. Thus, they may no longer perceive changes in interest rates and the use of leverage as threat to their farm business. 


\section{Conclusions}

Farm managers, like other business owners, must identify and manage risk in the course of their business operations. As machinery and other farm input costs continue to drift upwards, the capital requirements necessary to stay in business increase and farmers are put under pressure to find innovative ways of protecting margins and preserving working capital. Moreover, other factors such as unpredictable weather conditions, variation in output prices, policy changes, and global market trends all contribute to an increase in the risks that farmers face. Successful farm managers are those who can identify these risks and employ the necessary strategies to manage them.

Although all farm operators face risks, the perception of these risks by producers is not homogenous. The work of Thompson et al. (2019) was one of the first to show how different farms rate sources of risk among a varied cross section of United States agricultural producers. In our study, we examine a similar question using a slightly more homogeneous sample population. Using a count-based approach, we find that even within a population grain and oilseed farms in Saskatchewan, Canada, there is still considerable heterogeneity of risk ratings. Therefore, standardizing risks farmers face or taking all risks to be equally important to different categories of farmers could produce inappropriate results in terms of strategies designed to manage them. As has been suggested by other authors, the sources of risk and their severity is influenced by several factors, including location and farm type, as well as the tools available to manage risk. Moreover, the importance of a particular risk to farmers is moderated by their perception of that risk, farm and farmer characteristics, and the perceived and actual ability of the producers to manage these risks. This suggests that the perception of the type and severity of risks that farmers consider important may vary from place to place, which necessitates the need to understand these perceptions.

The analysis in this paper has focused on a sample of grain and oilseed farmers in Saskatchewan. Future studies may blend the approaches of this and the Thompson et al. (2019) study. A sample of producers that has geographic heterogeneity but sector homogeneity may provide a rich environment in which to examine how risks change due to location, while also allowing the researcher to examine how variation in the manager affects risks that might affect all producers equally (i.e. market access issues due to trade disputes). In Canada for example, the government of Alberta has in place the agriculture drought and excess moisture risk management plan, which is aimed at helping farmers to reduce production risks caused by variation in precipitation during the growing season.

The use of online and internet-based surveys could have created the possibility of not reaching many producers, especially those in remote areas where internet connectivity makes completing online surveys cumbersome and time consuming. However, we feel this concern is lessening based on the 2016 Census of Agriculture, which reports a significant improvement in internet access among the farm population in Saskatchewan. Out of about $61.3 \%$ of farms that use internet for farm business, $51.2 \%$ have access to high speed internet (Statistics Canada, 2016). The literature on BWS indicates that sensory fatigue could become a problem, however, we attempted to mitigate this by reducing the number of tasks to be performed. ${ }^{2}$

Our results show that grain and oilseed producers in Saskatchewan perceive production and marketing risks such as: (1) variation in output prices; (2) rainfall variability; (3) variation in input prices; (4) pests; and (5) diseases as important to their farm business. Farm managers are concerned with preserving margins, and the results on farmers' ranking of their perceived sources of risk confirms this. Respondents in our sample report that they are more concerned with risk factors that have direct impact on farm revenue. For example, inadequate rainfall, natural disasters, pests and diseases are all events that can reduce yield, which affects both the deliverable quantity and the graded quality of the production that is sold.

\footnotetext{
${ }^{2}$ Respondents completed all the BWS tasks, so we presume that these tasks were not overly burdensome.
} 
The BWS results provide useful insights to policy makers and government agencies, which should serve as guidance in designing programs and increasing awareness of current programs developed to manage risk on farms. For example, governments should continue to examine risk management tools such as AgriInsurance ${ }^{3}$ to ensure that coverage excludes normal risk that can be handled by farmers to focus on those beyond their control. Increased coverage in AgriInsurance will assist farmers in managing risks by lessening the financial impact of production losses due to natural hazards. In addition, policy makers in Canada should implement appropriate strategies to facilitate greater participation rate in AgriStability. ${ }^{4}$ Greater participation in margin protection programs will help farmers deal with risks resulting from input and output price variation considered important sources of risk to farmers in both clusters. The BWS results show agreement across respondents with regards to the importance of 'variation in output prices' to the farm business. There is also agreement among producers concerning the importance of risks such as 'rainfall variability' and 'variation in input prices'. Beyond these three sources of risk, respondents show some degree of heterogeneity in the ranking of the importance of the other risks.

Heterogeneity is revealed by results from both the BWS and the cluster analysis. The heterogeneity in responses means that promoting a one size fit all risk management tool may not necessary work. A more targeted approach may yield more appropriate results for individual producers. For instance, financial risks relating to interest rates and the debt-to-equity levels were ranked relatively low for the aggregate sample, yet these risks are quite significant to farmers in the 'Financial and business risk management' cluster. For producers in this cluster, strategies such as consolidating purchases of seed and other farm inputs may help by enabling them to benefit from discounts. Respondents in the 'Financial and business risk management' cluster also are less likely to have the income smoothing benefits of off-farm income. While there may be various reasons for not earning off-farm income, this risk mitigation tool has been shown to not only enhance the capacity of producers to repay debt (Briggeman, 2011) but also strengthen the ability of farm operators to internally finance farm operations and reduce that amount of farm revenue that goes into debt servicing. For other risks such as: (1) variation in output prices; (2) rainfall variability; (3) pests and diseases; and (4) changes in input prices, which respondents in both clusters consider important, strategies that target all farmers can be promoted. However, strategies that narrowly target farmers in dealing with financial and production quality risks will also be necessary.

\section{References}

Adamsen, J.M., S. Rundle-Thiele and J.A. Whitty. 2013. Best-worst scaling... reflections on presentation, analysis, and lessons learnt from case 3 BWS experiments. Market \& Social Research 21(1): 9-27.

Antón, J., C. Kimura and R. Martini. 2011. Risk management in agriculture in Canada. OECD Food, Agriculture and Fisheries Papers, No. 40. OECD Publishing, Paris, France. https://doi.org/10.1787/18156797

Auger, P., T.M. Devinney and J.J. Louviere. 2007. Using best-worst scaling methodology to investigate consumer ethical beliefs across countries. Journal of Business Ethics 70(3): 299-326.

Beckie, H.J., A.G. Thomas, A. Légère, D.J. Kelner, R.C. Van Acker and S. Meers. 1999. Nature, occurrence, and cost of herbicide-resistant wild oat (Avena fatua) in small-grain production areas. Weed Technology 13(3): 612-625.

Boggess, W.G., K.A. Anaman and G.D. Hanson. 1985. Importance, causes, and management responses to farm risks: evidence from Florida and Alabama. Southern Journal of Agricultural Economics 17(2): 105-116.

Briggeman, B.C. 2011. The importance of off-farm income to servicing farm debt. Economic Review, Federal Reserve Bank of Kansas City Q1: 63-82.

Chavas, J.P. and G. Shi. 2015. An economic analysis of risk, management, and agricultural technology. Journal of Agricultural and Resource Economics 40(1): 63-79.

\footnotetext{
${ }^{3}$ Agrilnsurance is the generic term used for the federal-provincial-producer cost shared crop insurance program in Canada that minimizes losses stemming from yield reductions due to natural hazards.

${ }^{4}$ AgriStability is a margin protection program that is triggered when reference margins (calculated as the Olympic average for the last five years of the farm) fall below $70 \%$.
} 
Cowan, M. 2018. Pulse industry worries about precedent as India slaps $60 \%$ tariff on chickpeas. CBC News, March 2, 2018. Available at: https://www.cbc.ca/news/canada/saskatchewan/india-chickpea-tariffpulse-industry-1.4559947

Dumbrell, N.P., M.E. Kragt and F.L. Gibson. 2016. What carbon farming activities are farmers likely to adopt? A best-worst scaling survey. Land Use Policy 54: 29-37.

El Benni, N. and R. Finger. 2012. Where is the risk? Price, yield and cost risk in Swiss crop production. Paper presented at the $28^{\text {th }}$ Triennial Conference of the International Association of Agricultural Economists (IAAE). August 18-24, 2012. Foz do Iguaçu, Brazil.

Erdem, S. and D. Rigby. 2013. Investigating heterogeneity in the characterization of risks using best worst scaling. Risk Analysis 33(9): 1728-1748.

Erdem, S., D. Rigby and A. Wossink. 2012. Using best-worst scaling to explore perceptions of relative responsibility for ensuring food safety. Food Policy 37(6): 661-670.

Fabozzi, F.J., S.M. Focardi, S.T. Rachev and B.G. Arshanapalli. 2014. The basics of financial econometrics: tools, concepts, and asset management applications. John Wiley \& Sons, Hoboken, NJ, USA.

Finn, A. and J.J. Louviere. 1992. Determining the appropriate response to evidence of public concern: the case of food safety. Journal of Public Policy \& Marketing 11(2): 12-25.

Flynn, T.N. 2010. Valuing citizen and patient preferences in health: recent developments in three types of best-worst scaling. Expert Review of Pharmacoeconomics \& Outcomes Research 10(3): 259-267.

Fraley, C. and A.E. Raftery. 1998. How many clusters? Which clustering method? Answers via model-based cluster analysis. The Computer Journal 41(8): 578-588.

Gabriel, S.C. and C.B. Baker. 1980. Concepts of business and financial risk. American Journal of Agricultural Economics 62(3): 560-564.

Ganesalingam, J., D. Stahl, L. Wijesekera, C. Galtrey, C.E. Shaw, P.N. Leigh and A. Al-Chalabi. 2009. Latent cluster analysis of ALS phenotypes identifies prognostically differing groups. PLoS ONE 4(9): e7107.

Goodman, S., L. Lockshin and E. Cohen. 2005. Best-worst scaling: a simple method to determine drinks and wine style preferences. Paper presented at the $2^{\text {nd }}$ International Wine Marketing Symposium. Sonoma, CA, USA. Available at: http://hdl.handle.net/2440/33743

Government of Saskatchewan. 2016. Saskatchewan agriculture exports 2016. Available at: http://publications. gov.sk.ca/documents/20/93964Saskatchewan\%20Agriculture\%20Exports\%202016.2.pdf

Guerin, L. and T. Guerin. 1994. Constraints to the adoption of innovations in agricultural research and environmental management: a review. Animal Production Science 34(4): 549-571.

Hansson, H. and C.J. Lagerkvist. 2012. Measuring farmers' preferences for risk: a domain-specific risk preference scale. Journal of Risk Research 15(7): 737-753.

Harwood, J.L., R. Heifner, K. Coble, J. Perry and A. Somwaru. 1999. Managing risk in farming: concepts, research, and analysis: US Department of Agriculture, Economic Research Service, No. 1473-2016120714. USDA, Washington, DC, USA.

Howden, D. 2016. Agricultural Producers Association of Saskatchewan: 2015/16 Farm Program Survey. Available at: https://apas.ca/pub/documents/News Releases/2016/BRM Survey Report final_April 22.pdf

Hwang, S.-F., S.E. Strelkov, G. Peng, H. Ahmed, Q. Zhou and G. Turnbull. 2016. Blackleg (Leptosphaeria maculans) severity and yield loss in canola in Alberta, Canada. Plants 5(31): 31

Kimura, S., J. Antón and C. LeThi. 2010. Farm level analysis of risk and risk management strategies and policies: cross country analysis. OECD Food, Agriculture and Fisheries Papers, No. 26. OECD Publishing, Paris, France. https://doi.org/10.1787/5kmd6b5rl5kd-en

Knutson, R.D., E.G. Smith, D.P. Anderson and J.W. Richardson. 1998. Southern farmers' exposure to income risk under the 1996 farm bill. Journal of Agricultural and Applied Economics 30(1): 35-46.

Koesling, M., M. Ebbesvik, G. Lien, O. Flaten, P.S. Valle and H. Arntzen. 2004. Risk and risk management in organic and conventional cash crop farming in Norway. Food Economics - Acta Agriculturae Scandinavica, Section C 1(4): 195-206.

Lagerkvist, C.J., 2013. Consumer preferences for food labelling attributes: comparing direct ranking and bestworst scaling for measurement of attribute importance, preference intensity and attribute dominance. Food Quality and Preference 29(2): 77-88. 
Lei, X., Q. Zhang, A.L. Zhou and H. Ran. 2013. Assessment of flood catastrophe risk for grain production at the provincial scale in China based on the BMM method. Journal of Integrative Agriculture 12(12): 2310-2320.

Loose, S.M. and L. Lockshin. 2013. Testing the robustness of best worst scaling for cross-national segmentation with different numbers of choice sets. Food Quality and Preference 27(2): 230-242.

Louviere, J.J. and G.G. Woodworth. 1991. Best-worst scaling: a model for the largest difference judgments. Working Paper, University of Alberta, Edmonton, Canada.

Louviere, J., I. Lings, T. Islam, S. Gudergan and T. Flynn. 2013. An introduction to the application of (case 1) best-worst scaling in marketing research. International Journal of Research in Marketing 30(3): 292-303.

MacCrimmon, K.R. and D.A. Wehrung. 1986. Taking risks: the management of uncertainty. Free Press, New York, NY, USA.

March, J.G. and Z. Shapira. 1987. Managerial perspectives on risk and risk taking. Management Science 33(11): 1404-1418.

Miller, D., M.F. Kets de Vries and J.M. Toulouse. 1982. Top executive locus of control and its relationship to strategy-making, structure, and environment. Academy of Management Journal 25(2): 237-253.

Mueller, S. and C. Rungie. 2009. Is there more information in best-worst choice data: using the attitude heterogeneity structure to identify consumer segments. International Journal of Wine Business Research 21(1): 24-40.

Nguyen, N., M. Wegener, I. Russell, D. Cameron, D. Coventry and I. Cooper. 2005. Risk management strategies by Australian farmers. Paper presented at the $15^{\text {th }}$ International Farm Management Conference. August 14-19, 2005. Campinas, SP, Brazil.

Ochieng, B.J. and J.E. Hobbs. 2016. Incentives for cattle producers to adopt an E. Coli vaccine: an application of best-worst scaling. Food Policy 59: 78-87.

Oerke, E.C. 2006. Crop losses to pests. The Journal of Agricultural Science 144(1): 31-43.

Patrick, G.R., P.N. Wilson, P.J. Barry, W.G. Boggess and D.L. Young. 1985. Risk perceptions and management responses: producer-generated hypotheses for risk modelling. Southern Journal of Agricultural Economics 17(2): 231-238.

Pellegrino, J.M. 1999. Risk management in agriculture: Argentine evidence of perceived sources of risk, risk management strategies and risk efficiency in rice farming. PhD-thesis, Lincoln University, Baltimore Pike, PA, USA.

Peterson, H.H. and T.L. Kastens. 2006. Organic grain farming in the United States: report of the findings from a nationwide survey part $i$ : summary of survey responses. Paper presented at the Risk and Profit Conference. August 17-18, 2006. Manhattan, KS, USA.

Rotter, J. 1966. Generalized expectancies for internal versus external control of reinforcement. Psychological Monographs 80(1): 609.

Savary, S., A. Ficke, J.N. Aubertot and C. Hollier. 2012. Crop losses due to diseases and their implications for global food production losses and food security. Food Security 4(4): 519-537.

Shapira, Z. 1986. Risk in managerial decision making. Hebrew University, Jerusalem, Israel, pp. 1404-1418.

Sherrick, B.J., P.J. Barry, P.N. Ellinger and G.D. Schnitkey. 2004. Factors influencing farmers' crop insurance decisions. American Journal of Agricultural Economics 86(1): 103-114.

Snipes, M. and D.C. Taylor. 2014. Model selection and Akaike information criteria: an example from wine ratings and prices. Wine Economics and Policy 3(1): 3-9.

Statistics Canada. 2016. Census of agriculture farm and farm operator data. Available at: http:/www5.statcan. gc.ca/cansim/a03?lang=eng\&pattern=004-0200..004-0246\&p2=31.

Statistics Canada. 2017. CANSIM table 001-0017. Estimated areas, yield, production of principal field crops by small area data regions, in metric and imperia units. Available at: https://www150.statcan.gc.ca/ t1/tbl1/en/tv.action?pid=3210035901

Statistics Canada. 2020a. Table 32-10-0442-01. Farm operators classified by number of operators per farm and age. https://doi.org/10.25318/3210044201-eng

Statistics Canada. 2020b. Table 32-10-0441-01. Farm operators classified by number of operators per farm and sex. https://doi.org/10.25318/3210044101-eng 
Statistics Canada. 2020c. Table 32-10-0024-01. Number of farm operators classified by farm type and educational attainment. https://doi.org/10.25318/3210002401-eng

Thompson, N.M., C. Bir and N.J.O. Widmar. 2019. Farmer perceptions of risk in 2017. Agribusiness 35(2): 182-199.

Tothova, M. 2011. Main challenges of price volatility in agricultural commodity markets. In: I. Piot-Lepetit and R'Barek (eds.) Methods to analyse agricultural commodity price volatility. Springer Science \& Business Media, New York, NY, USA, pp. 13-29.

Umberger, W.J., R. Stringer and S.C. Mueller. 2010. Using best-worst scaling to determine market channel choice by small farmers in Indonesia. Paper presented at the Agricultural \& Applied Economics Association 2010 AAEA, CAES, \& WAEA Joint Annual Meeting. July 25-27, 2010. Denver, CO, USA. Available at: https://core.ac.uk/download/pdf/6400798.pdf

Velandia, M., R.M. Rejesus, T.O. Knight and B.J. Sherrick. 2009. Factors affecting farmers' utilization of agricultural risk management tools: the case of crop insurance, forward contracting, and spreading sales. Journal of Agricultural and Applied Economics 41(1): 107-123.

Vermunt, J.K. and J. Magidson. 2002. Latent class cluster analysis. In: J. Hagenaars and A. McCutcheon (eds.) Applied latent class analysis. Cambridge University Press, Cambridge, UK, pp. 89-106.

Vermunt J.K. and J. Magidson. 2014. Analysing MaxDiff data with scale factors: applications of latent GOLD® Basic + Choice 5.0. Statistical Innovations Inc., Belmont, MA, USA. Available at: https:// www.statisticalinnovations.com/wp-content/uploads/LGChoice_tutorial_8A.pdf 
